\title{
Homograft conduit failure in infants is not due to somatic outgrowth
}

Winfield J. Wells, MDa
Hector Arroyo, Jr, MD
Ross M. Bremner, MD
John Wood, MD
Vaughn A. Starnes, MD

From the Departments of Cardiothoracic Surgery $^{\mathrm{a}}$ and Cardiology, ${ }^{\mathrm{b}}$ The Heart Institute at Children's Hospital Los Angeles, Keck School of Medicine, University of Southern California, Los Angeles, Calif.

Read at the Eighty-first Annual Meeting of The American Association for Thoracic Surgery, San Diego, Calif, May 6-9, 2001.

Received for publication May 14, 2001; accepted for publication May 18, 2001.

Address for reprints: Winfield J. Wells, MD, Associate Professor of Clinical Surgery, The Heart Institute at Children's Hospital Los Angeles, Keck School of Medicine, University of Southern California, Los Angeles, CA 90027 (E-mail: wwells@chla.usc.edu).

J Thorac Cardiovasc Surg 2002;124:88-96

Copyright ( $(2) 2002$ by The American Association for Thoracic Surgery

$0022-5223 / 2002 \$ 35.00+0 \quad \mathbf{1 2 / 6 / 1 2 1 1 5 8}$

doi: $10.1067 / \mathrm{mtc} .2002 .121158$
Objective: It has been assumed that the need for homograft replacement is due to somatic outgrowth, but this has not been adequately studied. Our objective was to identify reasons for homograft conduit failure.

Methods: The records and imaging studies of 40 patients undergoing homograft conduit replacement of the right ventricular outflow tract from 1996 to 2000 were retrospectively reviewed.

Results: The majority of patients had a diagnosis of tetralogy of Fallot $(\mathrm{n}=20)$ and truncus arteriosus $(\mathrm{n}=13)$. The median age at the initial operation was 8 months (0.25-108 months). The initial homograft sizes ranged from 9 to $22 \mathrm{~mm}$, and 28 conduits were of pulmonary origin. When comparing size of the initial homograft with patients' expected pulmonary valve diameter $(z=0)$, oversizing was noted to be +3 (range, $0.83-5.4$ ). Median interval to conduit failure was 5.3 years $(0.83-11.3$ years). At homograft replacement, only 12 patients had an existing conduit that was 1 SD below the homograft conduit size needed $(z \leq-1)$. Most conduits had important regurgitation, but this was rarely a primary reason for reintervention $(\mathrm{n}=$ 1). Reoperation was usually required for stenosis, with a median gradient of $53 \mathrm{~mm}$ $\mathrm{Hg}(20-140 \mathrm{~mm} \mathrm{Hg})$. Stenosis was further categorized angiographically as follows: homograft valvular stenosis (shrinkage; 21/40 [53\%]), distal anastomotic stenosis $(4 / 40[10 \%])$, conduit kinking (3/40 [8\%]), sternal compression (3/40 [8\%]), posterior shelf impingement (2/40 [5\%]), and somatic outgrowth (3/40 [8\%]). Replacement in 2 patients was for proximal hood aneurysm. Several patients (7/40 [18\%]) had stenosis at multiple levels. The average decrease in conduit diameter was $47 \%$ $(28 \%-73 \%)$.

Conclusions: Somatic outgrowth is seldom a primary reason for homograft conduit replacement of the right ventricular outflow tract. The most common cause for failure is conduit obstruction with thickening and shrinkage at the annular area. Conduit stenosis was responsible for failure in $53 \%$ of patients, technical issues were responsible for $30 \%$, and only $8 \%$ failed as a result of somatic outgrowth. Placement of a smaller homograft $(z=0)$ at the initial operation may decrease the incidence of conduit kinking, sternal compression, and posterior shelf impingement.

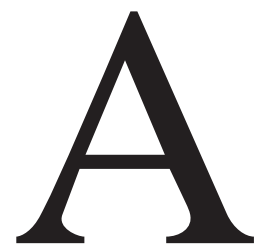

number of studies have documented the durability of homografts used for right ventricular outflow tract (RVOT) reconstruction. ${ }^{1-8}$ Although risk factors for conduit replacement have been described, little attention has been given to the exact mechanisms of conduit failure. The potential role of the immune system in the deterioration of homografts has also been increasingly explored, ${ }^{9-18}$ and this appears to be one logical explanation for the variability in 
TABLE 1. Diagnoses of patients undergoing conduit replacement

Tetralogy of Fallot with or without pulmonary atresia 20

Truncus arteriosus

Pulmonary atresia with IVS

Ross procedure

TGA with pulmonary stenosis

Double-outlet right ventricle

IVS, Intact ventricular septum; TGA, transposition of the great arteries.

conduit survival. To explore what factors may be contributing to homograft failure, we have reviewed our conduit replacement experience over the past 4 years.

\section{Methods}

A retrospective review of all patients undergoing RVOT homograft conduit replacement between 1996 and 2000 was carried out.

\section{Demographics at the Prior Conduit Placement}

Among the 40 study patients, the median age at prior conduit placement was 8 months $(0.25-108$ months), the weight was $6.7 \mathrm{~kg}$ $(2.7-26.1 \mathrm{~kg})$, and the body surface area (BSA) was $0.36 \mathrm{~m}^{2}$ $\left(0.18-0.97 \mathrm{~m}^{2}\right)$. The most common congenital heart defects in the group were tetralogy of Fallot (with or without pulmonary atresia, $\mathrm{n}=20)$ and truncus arteriosus $(\mathrm{n}=13)$. Table 1 lists the anatomic diagnosis for the entire group.

\section{Prior Homograft Procedure}

At the prior operation, 28 (70\%) of the 40 patients had a pulmonary homograft, and 12 had an aortic homograft. The average size of the prior conduit was $14 \mathrm{~mm}(9-21 \mathrm{~mm})$. Figure 1 shows the distribution of the sizes of the prior homograft. The $z$ value indexed to the patients' BSA at the prior implant was $+3(0.83-$ 5.4). Figure 2 shows the distribution of $z$ values for the homografts implanted at the prior operation. No attempt was made to match the donor and recipient for blood type. The technique of homograft placement at the prior operation could be determined in 37 of the 40 patients. In 17 patients the proximal anastomosis left the conduit in an extracardiac position, with the posterior half of the homograft anulus sutured to the epicardial aspect of the right ventriculotomy augmented by a hood of pericardium or homograft to complete the connection. The remainder had a more orthotopic or in situ proximal anastomosis where the posterior homograft anulus was sutured to the infundibular septum, and the entire connection was completed to the right ventriculotomy without an augmenting hood.

\section{Assesment Before Conduit Replacement}

After the initial conduit procedure, all patients were followed up by their cardiologist with serial echocardiography. When noninvasive testing showed evidence of important homograft dysfunction, cardiac catheterization was performed. In general, the indications for conduit replacement were a peak gradient across the RVOT of $50 \mathrm{~mm} \mathrm{Hg}$ or greater or a right ventricular (RV) pressure of $75 \%$ or greater when compared with systemic pressure. In

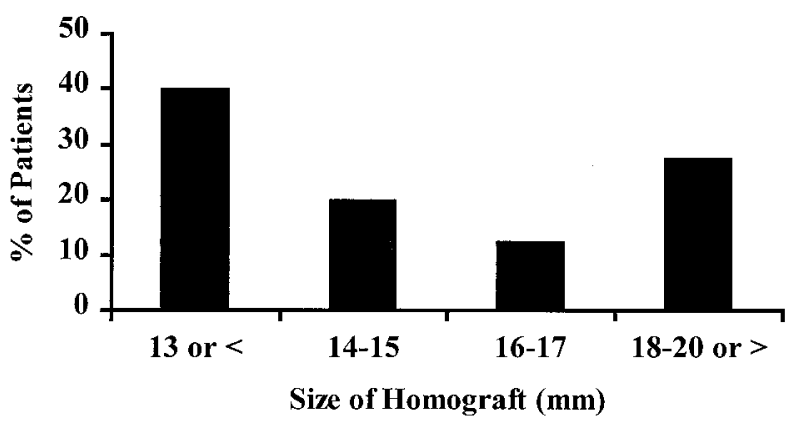

Figure 1. Distribution of initial conduit size.

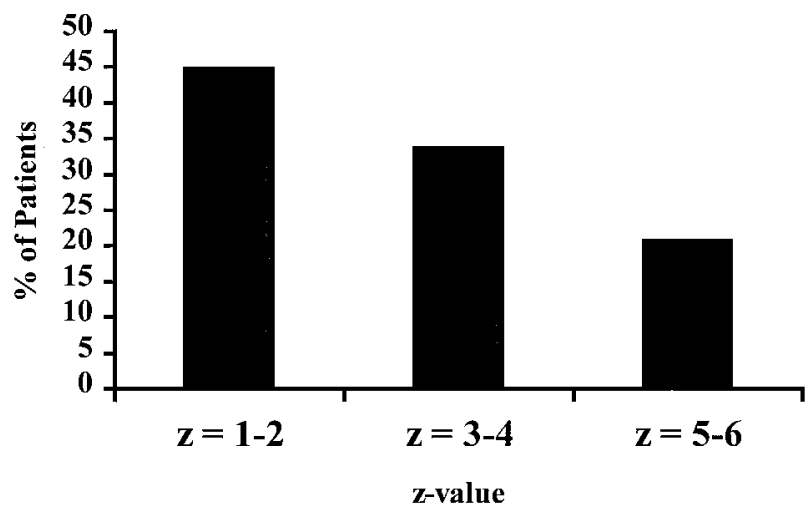

Figure 2. $Z$ values for the homografts at initial placement.

addition, severe pulmonary insufficiency leading to RV dilation and failure was occasionally an indication, as was aneurysmal dilation of the RV outflow in the region of the proximal conduit connection.

The prereplacement catheterization and angiography studies were independently reviewed by two of the authors, one of whom was a pediatric cardiologist. A consensus was then reached regarding the mechanism of conduit failure. When there was stenosis of the homograft, the cause of the obstruction was subcategorized as follows.

Conduit contracture or shrinkage. Conduit contracture or shrinkage (Figure 3) was characterized by concentric narrowing of the conduit lumen without evidence of important distortion or compression. The narrowing was usually at the annular area of the homograft but could extend more distally to include a part of or the entire tubular portion as well.

Conduit kinking. A sharp bend leading to distortion of the conduit was considered to be conduit kinking (Figure 4). This problem appeared to result from a combination of an extracardiac positioning of the homograft coupled with a more posterior lie of the pulmonary confluence. Excess length of the homograft might also contribute to this problem.

Sternal compression. Flattening of the conduit, particularly in the region of the proximal anastomosis, was occasionally attributed to sternal compression (Figure 5). Contributing factors could include a narrow anterior-posterior dimension of the chest cavity, dextrorotation of the heart (bringing the conduit under the sternum), or anatomic subtypes, such as corrected transposition of the great arteries (L-TGA) with RVOT obstruction, requiring the con- 


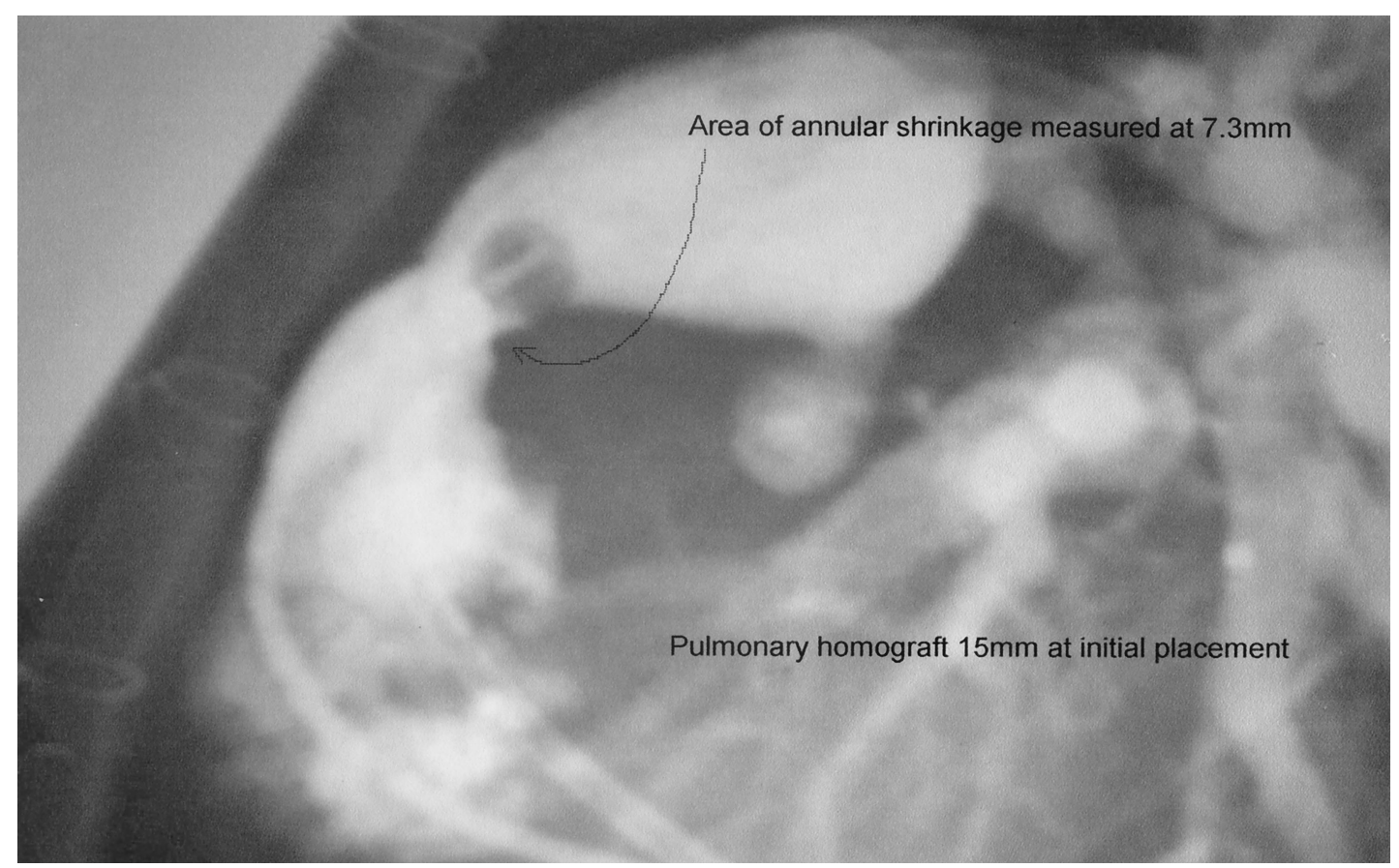

Figure 3. Angiographic image of a patient with conduit contracture (lateral projection).

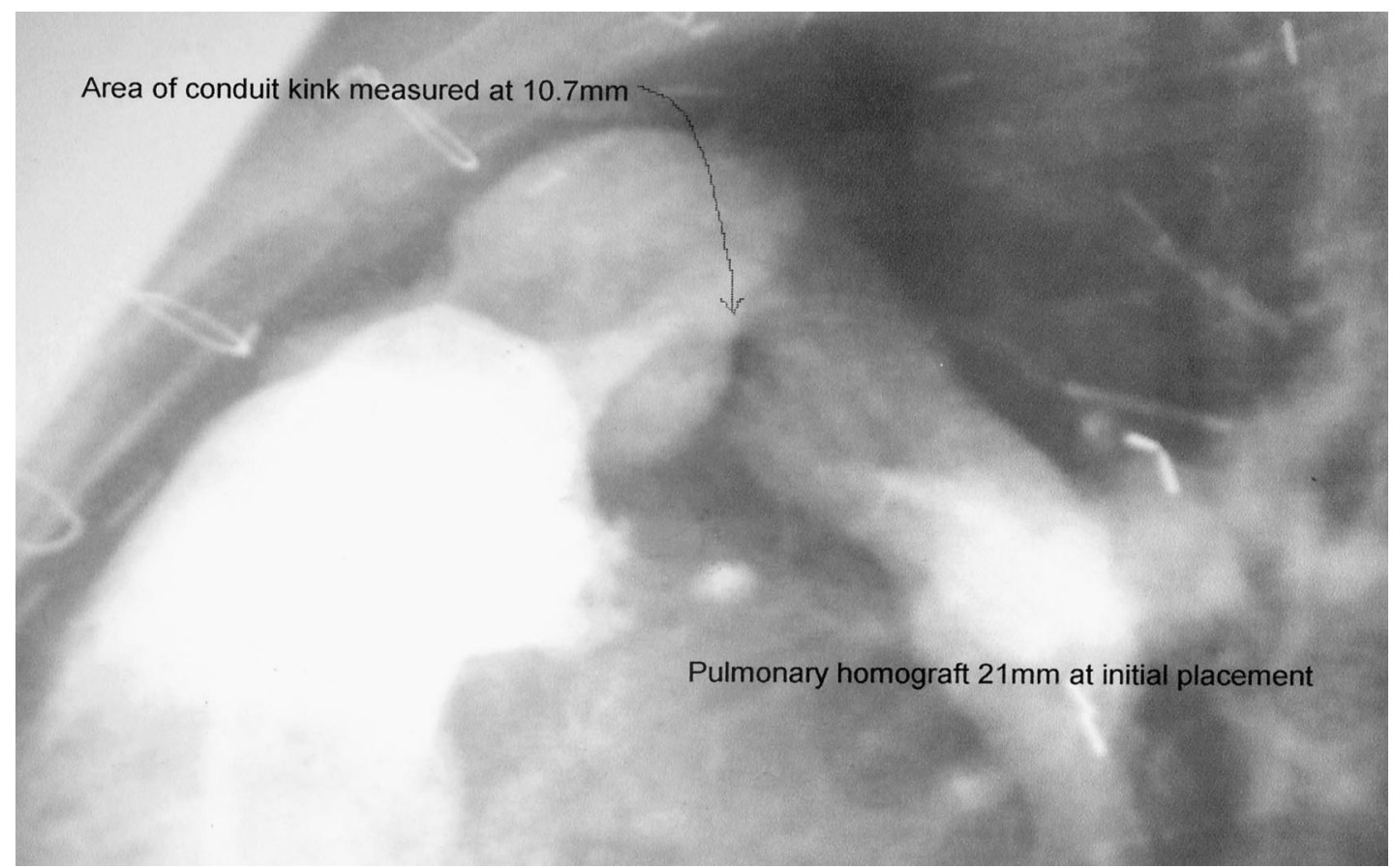

Figure 4. Angiographic image of a patient with conduit kinking (lateral projection).

duit to be placed to the right of the ascending aorta. Conduit oversizing was also thought to be a potential contributing factor to this problem.

Posterior muscle shelf impingement. This problem was characterized by a posterior indentation just distal to the homograft valve (Figure 6). This represents RV muscle mass, which lies between the right ventriculotomy and the pulmonary artery. Pulling the proximal anastomosis down into the RVOT to accomplish a more in situ or orthotopic positioning of the conduit may increase the likelihood of this problem. 


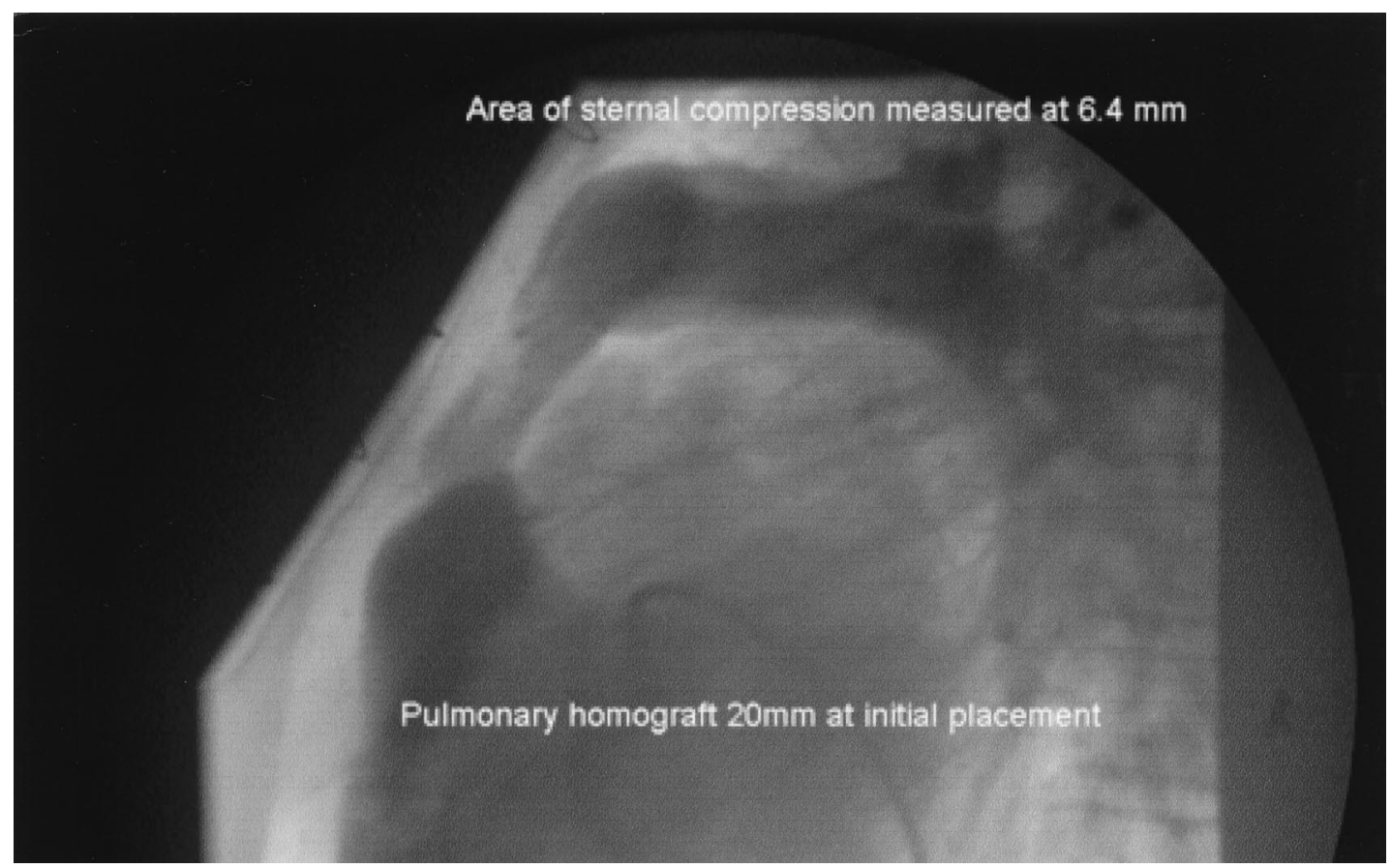

Figure 5. Angiographic image of a patient with sternal compression (lateral projection).

Distal anastomotic stenosis. When the gradient was clearly at the distal suture line, the problem was labeled as distal anastomotic stenosis.

Virtually all of the conduits had some degree of homograft valve insufficiency, although this was seldom the controlling factor in the decision to replace the valve. Insufficiency was graded as mild, moderate, or severe on the basis of both echocardiographic and angiographic data.

\section{Demographics at Conduit Replacement}

Age at conduit replacement was 7.8 years (1.3-16 years), weight was $21.1 \mathrm{~kg}(9-67 \mathrm{~kg})$, and BSA was $0.87 \mathrm{~m}^{2}\left(0.45-1.8 \mathrm{~m}^{2}\right)$.

\section{Technique of Conduit Replacement}

The replacement operation was through a resternotomy in all but one patient who, because of multiple previous midline sternotomies and evidence of conduit-sternal continuity, had a clamshell approach. In 3 of the 39 resternotomies, femoral cannulation was required because of conduit erosion into the sternum with bleeding problems on re-entry. For most cases, the majority of the old homograft tissue was completely resected, and the new conduit or monocusp was placed into the previous site. In 36 patients the replacement conduit was a cryopreserved pulmonary homograft. The remaining 4 patients had a monocusp fashioned from pulmonary homograft tissue. No augmentation hoods were needed. One patient who had 2 prior homograft failures from sternal compression caused by an unfavorable anatomic lie had the new conduit rerouted from the apex of the pulmonary ventricle around the right border of the heart up to the right pulmonary artery.

The median size of the conduits used for replacement was 21 $\mathrm{mm}(13-27 \mathrm{~mm})$. The $z$ value of the new homograft pulmonary anulus was $+5(2.5-8.3)$.

\section{Results}

There were no hospital deaths among the 40 patients undergoing conduit replacement. Important complications included 1 patient with a right diaphragm paresis and one patient who was reoperated on for closure of a fistula between the right pulmonary artery and the superior pulmonary vein discovered after conduit replacement. The median hospital stay was 3 days (2-10 days).

\section{Indications for Conduit Replacement}

The most common indication for conduit replacement was stenosis, which was present in 37 (96\%) of the 40 patients. Other infrequent primary indications were RVOT aneurysm formation in $2(5 \%)$ patients and conduit insufficiency in 1 (3\%) patient. The average time to conduit failure in this series was 5.3 years $(0.83-11.3$ years). The peak systolic gradient across the RVOT before conduit replacement was $52.5 \mathrm{~mm} \mathrm{Hg}$ (20-140 $\mathrm{mm} \mathrm{Hg}$ ), as measured during catheterization. This value was slightly lower than the average gradient measured by means of echocardiography, which was $59 \mathrm{~mm} \mathrm{Hg}(12-100 \mathrm{~mm} \mathrm{Hg})$. All of the conduits scheduled for replacement had some degree of homograft valve insufficiency. This was graded as mild in 17 and moderate in 14 , and the remaining 6 were believed to have severe regurgitation.

\section{Mechanisms of Conduit Stenosis}

When stenosis was the primary indication for conduit replacement, the median decrease in conduit diameter was 


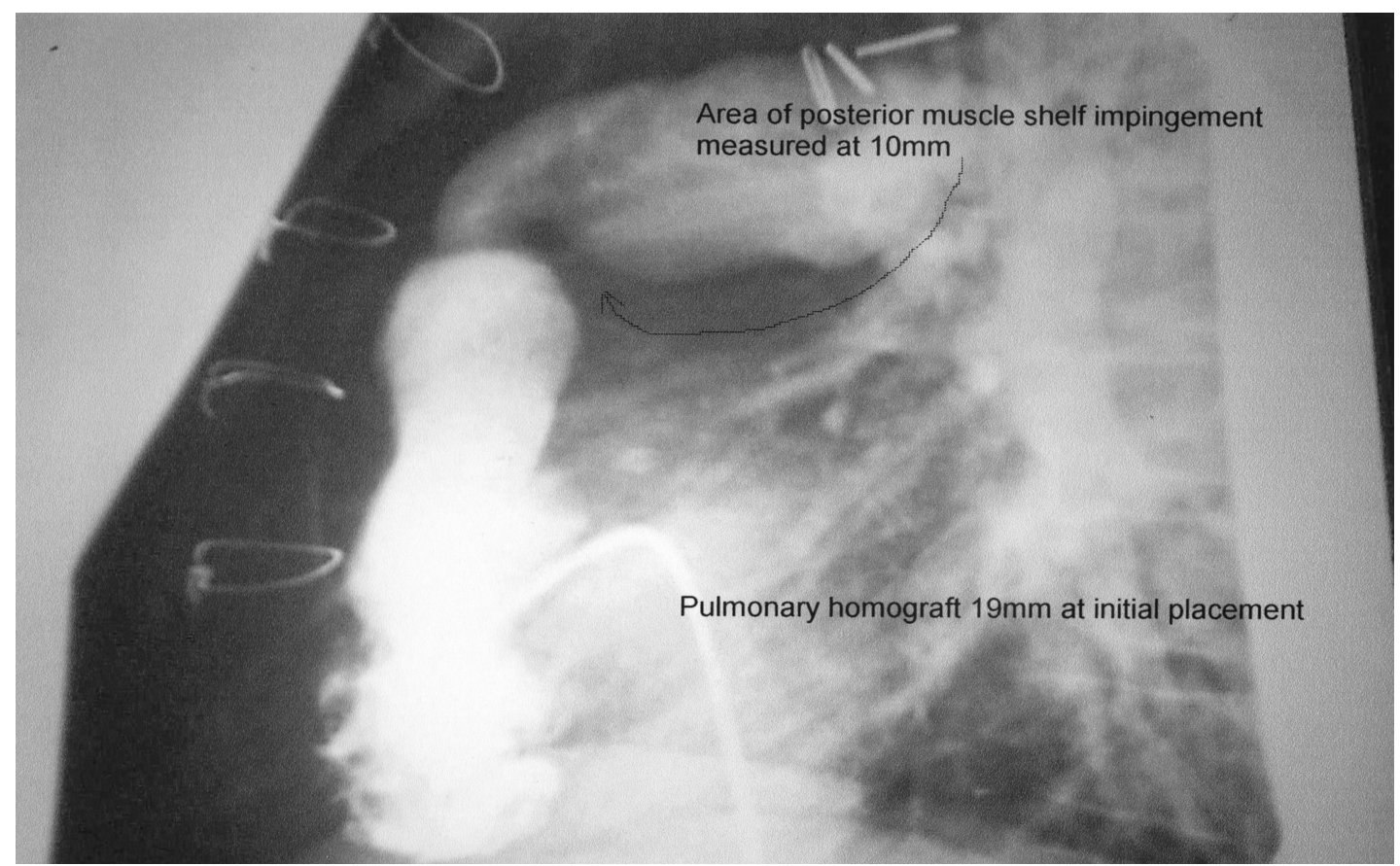

Figure 6. Angiographic image of a patient with posterior muscle shelf impingement (lateral projection).

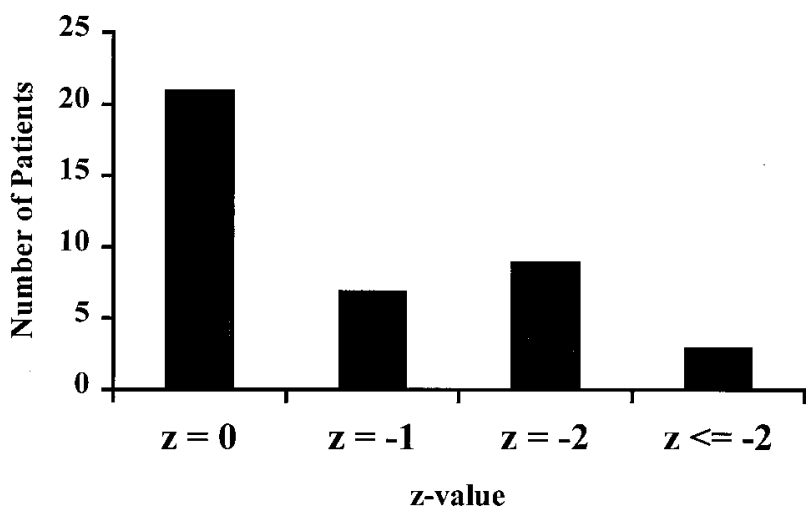

Figure 7. $Z$ value of the initial homograft anulus indexed to BSA at conduit replacement.

$47.4 \%(28 \%-73 \%)$ when compared with the annular size at the time of implantation. The diameter of the stenotic homografts averaged $7.6 \mathrm{~mm}(4.8-12 \mathrm{~mm})$. The primary mechanism of stenosis was categorized into subsets including homograft valvular and perivalvular contracture or shrinkage (21 [53\%]), conduit kinking (4 [10\%]), distal anastomotic stenosis (4 [10\%]), sternal compression (3 [8\%]), and posterior shelf impingement (2 [5\%]). In $3(8 \%)$ cases the patient appeared to have outgrown an otherwise well-functioning homograft. Table 2 depicts the incidence of these subgroups. In these somatic outgrowth cases, the $z$ value for the conduit valve was greater than -2 , indicating a valve diameter that would be expected to be obstructive.
TABLE 2. Incidence of homograft conduit stenosis by subgroup

\begin{tabular}{ll}
\hline Conduit contracture or shrinkage & $21(53 \%)$ \\
Technical issues & $12(30 \%)$ \\
Distal anastomotic stenosis & 4 \\
Conduit kinking & 3 \\
Sternal compression & 3 \\
Posterior shelf impingement & 2 \\
Multiple levels of stenosis & $7(17 \%)$ \\
\hline
\end{tabular}

There were multiple levels of conduit stenosis in 7 (18\%) of the 40 patients.

\section{$Z$ Values at the Time of Replacement}

The patient's normal expected size for the pulmonary valve at the time of reoperation was compared with the size of the homograft placed at the prior operation. The $z$ value for the failed conduits was thus determined. On the basis of this analysis, only 3 patients had a conduit that was more than 2 SDs $(z \geq-2)$ below normal, and in only 21 patients was the valve to be replaced smaller than normal $(z \geq 0)$. This information is summarized in Figure 4.

\section{Histology of the Explanted Homograft Tissue}

The most consistent histiologic finding among conduits removed for contracture was fibrointimal proliferation with narrowing of the lumen. These findings may be associated with a response to mechanical injury resulting from flow turbulence, a manifestation of chronic rejection to the graft, or both. 


\section{Discussion}

Although cryopreserved allografts are generally considered to be the best valved conduits for reconstruction of the RVOT, their durability is far from ideal. A number of studies have documented the actuarial freedom from homograft valve failure. ${ }^{1-8}$ In general, the failure rate is about $40 \%$ at 10 years. These same reports have documented both univariant and multivariant risk factors for homograft failure. The most consistent multivariant risk factors include smaller homograft diameter, younger recipient age, and weight. Additionally, aortic homografts have been found to fail more rapidly than conduits of pulmonary origin. ${ }^{2,4,5,7,8}$ Anatomic substrate has also been correlated with homograft longevity with truncus arteriosus, transposition, and doubleoutlet right ventricle associated with earlier failure. ${ }^{1,7}$

It has been assumed that homograft failure in younger recipients is often due to somatic outgrowth. The findings in this study suggest that although this occurs, it is unusual. At the time of replacement, most homograft valves have a diameter that should not be obstructive. Previous reports have attempted to categorize the causes of homograft failure. Sano and colleagues, ${ }^{19}$ in 1991, detailed the indications for conduit replacement and the sites of conduit obstruction in 43 patients. These were described as extracardiac conduits, and conduit obstruction at the valvular level was cited as the most common indication. Bando and coworkers ${ }^{8}$ also reported on the indications for homograft replacement in 42 patients. In this series homograft stenosis was the primary indication for reoperation in $69 \%$ of patients.

Among the 40 failed homografts in this series, stenosis caused by contracture was the most common indication for reoperation. The cause of this contracture is not exactly known, but there is increasing evidence that the immune system may be playing a major role. Early work by Cochran and Kunzelman ${ }^{9}$ demonstrated that cryopreservation does not alter antigenic expression of allografts. The cellular viability, which was believed to be so important for cryopreserved homograft valve durability, may well provide the antigenicity that leads to graft destruction. Preservation of endothelial and valve architecture suggests that it is an immunologic reaction rather than the cryopreservation process itself that is responsible for the degenerative process. ${ }^{10}$

Extensive work has been carried out demonstrating the role of the humoral immune response after implantation of cryopreserved allografts into pediatric patients. ${ }^{11-14}$ Hawkins and colleagues ${ }^{11}$ have shown that cryopreserved allograft tissue induces a marked response that involves both class I and class II anti-HLA antibodies within 3 months. These HLA antibodies have been shown to persist for more than a year after the operation. ${ }^{12}$

Cell-mediated immune response has also been shown in the degeneration of cryopreserved homografts. ${ }^{15-18}$ Ranjani and colleagues ${ }^{15}$ found that among 5 children with failed homografts, all had inflammation consisting of $\mathrm{T}$ and $\mathrm{B}$ lymphocytes in their explanted tissue. Work on a sheep model demonstrated that lymphocytes are present in cryopreserved homografts up to 12 months after implantation. ${ }^{10}$ In addition, lymphocyte cultures have been propagated in an interleukin 2-conditioned medium from explanted homografts, ${ }^{16}$ and recent experimental work has shown that allograft heart valves in the rat model undergo $\mathrm{T}$ cellmediated immune rejection, resulting in structural failure. ${ }^{17}$

Both animal models and human studies have demonstrated histopathologic evidence consistent with rejection within explanted cryopreserved homografts. Using a rat model, Motomura and colleagues ${ }^{18}$ were able to show that after allotransplantation of cryopreserved rat aorta, intimal thickening, medial necrosis, and cellular infiltration in the adventitia (all manifestations of rejection) were present. ${ }^{18}$ In a study by Ranjani and coworkers, ${ }^{15} 5$ homograft valves explanted from infants with rapid conduit failure showed lymphocytic infiltration within the valve leaflets and aortic sleeves consistent with rejection. These findings have lead to the consideration of the use of immune suppression for patients undergoing homograft implantation. A report prospectively evaluating the use of azathioprine on the humoral immune response and homograft function in children receiving valved allografts found no significant decrease in immune response to HLA antibodies or in the function of the cryopreserved valves in the treated versus the control group. ${ }^{20}$

Homograft insufficiency was the primary indication for conduit replacement in only one patient but was universally present. In fact, insufficiency is probably an important contributing factor to conduit failure because the additional volume load that comes with valve regurgitation heightens the gradient across a stenotic conduit. Therefore, preservation of valve structural integrity is important in prolonging homograft durability.

Although intrinsic contracture was the most common cause for homograft stenosis in this series, anatomic distortion may also play a significant role. Sternal compression may lead to homograft valve annular distortion. Turbulence created by this distortion may be partially responsible for valve deterioration with loss of function. The nearly universal finding of valve insufficiency associated with the aging of homograft conduits suggests the likely high incidence of this distortion problem. It has been our experience that marked oversizing of conduits, particularly in infants, may be counterproductive because conduit distortion may lead to more rapid deterioration than if a smaller size had been chosen. In addition, certain anatomic variants seem to predispose to conduit compression and more rapid failure. An example from this series is L-TGA with pulmonary stenosis or atresia requiring conduit reconstruction. Because the conduit must be positioned to the right of the aorta, it by 
necessity lies immediately beneath the sternum. One of our patients experienced 2 conduit failures after the usual homograft routing for L-TGA with pulmonary atresia. The patient also had a relatively narrow anterior-posterior chest diameter. This patient eventually had conduit replacement with rerouting to bring the conduit from the apex of the pulmonic ventricle and then following a curving course along the right heart back up to the inferior aspect of the right pulmonary artery successfully, avoiding the sternal compression problem.

A potential solution to the problem of conduit distortion could be to reinforce the homograft anulus with a rigid ring. It might be helpful to have such support both at the anulus and sinotubular junction to ensure optimal leaflet alignment.

Another potentially important technical issue involves the positioning of the proximal conduit anastomosis. If the homograft is sewn posteriorly to the epicardial aspect of the ventriculotomy, it tends to sit much higher (extracardiac). A hood is then needed to provide a smooth outflow tunnel. This extracardiac positioning would seem to be more susceptible to compression and homograft distortion. The alternative is to bring the proximal anastomosis down into the RVOT, sewing the posterior anastomotic suture line to the infundibular septum. In this case the anterior aspect of the connection can usually be sewn primarily to the ventriculotomy. This in situ or orthotopic positioning has a lower profile but may distort the homograft annular region by posterior muscle impingement posteriorly, which indents the homograft as the conduit emerges from the RVOT over a muscle shelf.

We propose that the optimal model for judging homograft durability comes when conduits are placed during the Ross procedure. Because the pulmonary tree is undistorted and the homograft can be trimmed to fit precisely into the autograft bed, this anatomic subtype should give us the best information about intrinsic homograft durability. Early results from our Ross experience and that of others ${ }^{6}$ suggests improved durability of homografts in these patients compared with in other anatomic subtypes.

The ideal conduit is one that would posses both excellent long-term durability and the potential for growth. Engineering of a valved conduit made from a patient's own cells may offer these properties. Early experience with tissue engineering has been encouraging. ${ }^{21,22}$ Goldstein and colleagues ${ }^{21}$ recently reported their work on a bioengineered xeno-autograft. A composite valve made from decellularized porcine aortic leaflets was implanted into a weanling sheep. After several months, the valves were found to have recellularized, and the short-term function was good. Other centers are working on a biodegradable and biocompatible scaffold that can be seeded with a patient's own vascular cells in vitro and subsequently implanted. Using a lamb model with a scaffold made out of polyhydroxyalkanoates, reasonable function of trileaflet heart valves has been observed for up to 120 days..$^{22}$ Although work with engineered autografts is very new, these early results are promising. Meanwhile, further work to investigate the mechanisms of cryopreserved homograft failure, specifically establishing a clearer role of the immune system in homograft degeneration, is warranted.

\section{References}

1. Gerestein CG, Takkenberg JJM, Oei FBS, Cromme-Dijkhuis AH, Spitaels SEC, et al. Right ventricular outflow tract reconstruction with an allograft conduit. Ann Thorac Surg. 2001;71:911-8.

2. Forbes JM, Shah AS, St Louis JD, Jaggers JJ, Ungerleider RM. Cryopreserved Homografts in the pulmonary position: determinants of durability. Ann Thorac Surg. 2001;71:54-40.

3. Bielefeld MR, Bishop DA, Campell DN, Mitchell MB, Grover FL, Clarke DR. Reoperative homograft right ventricular outflow tract reconstruction. Ann Thorac Surg. 2001;71:482-8.

4. Caldarone CA, McCrindle BW, Van Arsdell GS, Coles JG, Webb G, Freedom RM, et al. Independent factors associated with longevity of prosthetic pulmonary valves and valved conduits. J Thorac Cardiovasc Surg. 2000;120:1022-31.

5. Tweddell JS, Pelech AN, Frommelt PC, Mussatto KA, Wyman JD, et al. Factors affecting longevity of homograft valves used in right ventricular outflow tract reconstruction for congenital heart disease. Circulation. 2000;102(suppl):III-130-5.

6. Niwaya K, Knott-Craig, CJ, Lane MM, Chandrasekaren K, Overholt ED, Elkins RC. Cryopreserved homograft valves in the pulmonary position: risk analysis for intermediate-term failure. J Thorac Cardiovasc Surg. 1999;117:141-7.

7. Stark J, Bull C, Stajevic M, Jothi M, Elliot M, de Leval M. Fate of subpulmonary homograft conduits: determinants of late homograft failure. J Thorac Cardiovasc Surg. 1998;115:506-16.

8. Bando K, Danielson GK, Schaff HV, Mair DD, Julsrud PR, Puga FJ. Outcome of pulmonary and aortic homografts for right ventricular outflow tract reconstruction. J Thorac Cardiovasc Surg. 1995;109: 509-18.

9. Cochran RP, Kunzelman KS. Cryopreservation does not alter antigenic expression of aortic allografts. J Surg Res. 1989;46:597-9.

10. Neves JP, Gulbenkian S, Ramos T, Martins AP, Caldas MC, Mascarenhas R, et al. Mechanisms underlying degeneration of cryopreserved vascular homografts. J Thorac Cardiovasc Surg. 1997;113: 1014-21.

11. Hawkins JA, Breinholt JP, Lambert LM, Fuller TC, Profaizer T, McGough EC, et al. Class I and class II anti-HLA antibodies after implantation of cryopreserved allograft material in pediatric patients. J Thorac Cardiovasc Surg. 2000;119:324-30.

12. Shaddy RE, Hunter DD, Osborn KA, Lambert LM, Minich LL, Hawkins JA, et al. Prospective analysis of HLA immunogenicity of cryopreserved valved allografts used in pediatric heart surgery. Circulation. 1996;94:1063-7.

13. Hoekstra FME, Witvliet M, Knoop CY, Wassner C, Bogers C, Weimar W, et al. Immunogenic human leukocyte antigen class II antigens on human cardiac valves induce specific alloantibodies. Ann Thorac Surg. 1998;66:2022-6.

14. Hoekstra F, Witvliet M, Knoop C, Akkersdijk G, Jutte N, Boggers A, et al. Donor-specific anti-human leukocyte antigen class I antibodies after implantation of cardiac valve allografts. J Heart Lung Transplant. 1997; 16:570-2.

15. Rajani B, Mee RB, Ratliff NB. Evidence for rejection of homograft cardiac valves in infants. J Thorac Cardiovasc Surg. 1998;115:111-7.

16. Hoekstra F, Knoop C, Vaessen L, Wassenaar C, Jutte N, Bos E, et al. Donor-specific cellular immune response against human cardiac valve allografts. J Thorac Cardiovasc Surg. 1996;112:281-6.

17. Legare JF, Lee TDG, Creaser K, Ross DB. T lymphocytes mediate leaflet destruction and allograft valve failure in rats. Ann Thorac Surg. 2000;70:1238-45. 
18. Motomura N, Imakita M, Yutani C, Kitoh Y, Kawashima Y, Oka T. Histological change in cryopreserved rat aortic allograft. J Cardiovasc Surg. 1995;36:53-60.

19. Sano S, Karl TR, Mee RBB. Extracardiac valved conduits in the pulmonary circuit. Ann Thorac Surg. 1991;52:285-90.

20. Shaddy RE, Lambert LM, Fuller TC, Profaizer, Thompson DD, Baker SI, et al. Prospective randomized trial of azathioprine in cryopreserved valved allografts in children. Ann Thorac Surg. 2001;71:43-8.

21. Goldstein S, Clarke DR, Walsh SP, Black KS, O'Brien MF. Transpecies heart valve transplantation: Advanced studies of a bioengineered xeno-graft. Ann Thorac Surg. 2000;70:1962-9.

22. Sodian R, Hoerstrup SP, Sperling JS, Daebritz S, Martin DP, Moran $\mathrm{AM}$, et al. Early in vivo experience with tissue-engineered trileaflet heart valves. Circulation. 2000;102(suppl):III-22-9.

\section{Discussion}

Dr John W. Brown (Indianapolis, Ind). I agree with most of your conclusions. I do have a couple of comments.

First, pulmonary homografts have been pretty disappointing, both in our hands and in yours.

Second, in your service $50 \%$ of the pulmonary homografts had shrunk to half their size within 5 years. When you went back to reoperate on them, you put in a second pulmonary homograft. Why? Is that all you had to use? Did you consider other techniques? A simple patch or a monocusp patch might be better than putting a second pulmonary homograft in the patient when that first one failed within 5 years.

Third, when you reoperated on these patients for their second conduit, you exposed the femoral vessels on 39 of the 40 patients. Have you not used the polytetrafluoroethylene membrane to cover the right heart and conduit when you do your initial correction? I know that we have used the polytetrafluoroethylene pericardial membrane in more than 500 patients now. I have not encountered a problem with it, and its presence allows me to relax a lot more when the resident is using the oscillating sternal saw for the redo sternotomy.

I enjoyed your beautiful presentation. I agree with your results. I, too, am disappointed with pulmonary homografts.

I have one further question. Did you measure panel-reactive antibodies in your patients to see whether they had an immune reaction to these initial homografts? Did you speculate some sort of a mechanical factor with turbulence causing these homografts to deteriorate more quickly than would have anticipated?

Dr Wells. Thank you, John. I will take your points in reverse order.

We did not measure panel-reactive antibodies. There are an increasing number of studies coming out looking at this, particularly as some of the newer ideas in how to reduce the immunogenicity of homografts are coming forward.

On the second point you made, actually we had 3 patients in whom we had to cannulate the femoral vessels because of an adventurous sternal opening.

We do not routinely use membranes unless we think the conduit is going to be up near the sternum, in which case we do. But we did have 3 of the 40 patients in whom we had to cannulate the femoral artery; otherwise, they were all standard cannulations.

Finally, why do we keep using homografts? I guess one way to answer would be that we do not know what is better yet. There may be some things on the horizon that could be better. The idea that we should be preserving the cellularity of homografts to make them viable may have been completely wrong. Maybe the better thing to do is have no living cells in these homograft conduits and let the patient repopulate them. We are quite interested in that concept and think it may be better.

We have, more recently, since we put together this series, implanted some stented xenograft bioprostheses into patients, particularly larger patients in whom we are doing a homograft replacement, believing that there is some evidence that they may actually be more durable than the homografts themselves. I know there are some other new ideas, John, including the bovine conduits that are under investigation, and we are very interested in the outcomes of those sorts of conduits. Almost anything might be better than what we have.

Dr John E. Mayer (Boston, Mass). I would like to offer one other hypothesis for your consideration. Given the fact that the homografts probably do not grow in length, if the right ventriculotomy to pulmonary artery bifurcation distance increases, then one has the famous Chinese finger puzzle phenomenon. My impression is that this not infrequently causes the homograft diameter to narrow as it is asked to elongate. I wondered what your thoughts might be about that and whether that does not explain at least some of the diffuse narrowing that occurs throughout the length of some of the homografts.

Dr Wells. Thank you, John. I do not know that you are wrong. I suspect that as that lengthening process goes on, the native vessels would be more likely to be compliant and come toward the homograft, but I cannot disprove your theory.

Dr Brown. Twenty of your 40 patients had tetralogy or tetralogy complex. I know at our institution we almost never use a conduit for tetralogy. Is there a different kind of tetralogy in Los Angeles?

Even in the children with acquired pulmonary atresia, you can bring the proximal main pulmonary artery down to the RVOT and then either roof it over with a simple patch or, as we do, put a monocusp in and then roof it over with a patch. It sounds like you are throwing away the native back wall of the RVOT when you inset a conduit in tetralogy and its variants. Why?

Dr Wells. For most of these tetralogies, John, I think it is a question of terminology. These are really tetralogy of Fallot/ pulmonary atresia, ventricular septal defect/pulmonary atresia, whatever you want to call them. There is more of those variants than there are just hypoplastic anuli. It is a question of terminology more than anything else.

Dr Francois Lacour-Gayet (Hamburg, Germany). I totally agree with you that the patients do not outgrow their homografts.

Finally, you define in this way a sort of outgrowth age or outgrowth time. Can you try to assign a number to that? For example, how much time must pass after a conduit is placed in a neonatal repair of truncus arteriosus before it is acceptable to say that the patient has outgrown the valved conduit?

My second point is that, contrary to your experience, we have observed severe insufficiency with homografts, especially in truncus. Personally, I have seen total disappearance of the leaflets of the homograft several times. Have you seen this and do you suspect an immunologic process.

Dr Wells. Thank you for your comments. I will take the last one first.

I hope I did include in my remarks the fact that most of these homografts had a good deal of insufficiency, some moderate and some severe. I would agree, when you look at these contracture- 
shrinkage patients, you cannot find the leaflets. It has all become fibrosed. One of the things that is hard to do is to determine the histologic features, because by the time you go back, it is at the end stage of the process, and it is all just fibrosed and gone.

I agree with you that insufficiency is playing a role here. Usually it is a gradient that is driving the patient back to you for homograft replacement. The cardiologist is sending him back saying there is stenosis here, and it is rarely just pure insufficiency. At least that is our experience.
Finally, with regard to outgrowing the homograft: Usually when these homografts are implanted, they are at least 2 to 3 and sometimes 5 SDs larger than what is appropriate for the patient's weight. After this destruction has taken place, the patient still has a big enough anulus if the homograft has not been affected by this process. That is what I meant by "outgrow." I mean they have a big enough anulus; it is just that the anulus is contracted or shrunken. This is usually about a 5- to 7-year process on the basis of this experience.

\section{Bound volumes available to subscribers}

Bound volumes of The Journal of Thoracic and Cardiovascular Surgery are available to subscribers (only) for the 2002 issues from the Publisher, at a cost of $\$ 134.00$ for domestic, $\$ 165.85$ for Canadian, and $\$ 155.00$ for international subscribers for Vol 123 (January-June) and Vol 124 (July-December). Shipping charges are included. Each bound volume contains a subject and author index and all advertising is removed. The binding is durable buckram with the Journal name, volume number, and year stamped in gold on the spine. Payment must accompany all orders. Contact Mosby, Subscription Customer Service, 6277 Sea Harbor Dr, Orlando, FL 32887, USA; phone 800-654-2452 or 407-345-4000.

Subscriptions must be in force to qualify. Bound volumes are not available in place of a regular Journal subscription. 